\title{
Üniversite Öğrencilerinin Obezite Farkındalıkları ile Beden Kitle İndeksleri Arasındaki iliş̧ki
}

\author{
İlknur Özkan®, Derya Adıbelli®, Emine İlaslan®, Seçil Taylan®
}

Akdeniz Üniversitesi Kumluca Sağlık Bilimleri Fakültesi, Hemşirelik Bölümü, Antalya, Türkiye

İlknur Özkan, Dr. Öğr. Üyesi Derya Adıbelli, Dr. Öğr. Üyesi Emine Illaslan, Öğr. Gör. Seçil Taylan, Dr. Öğr. Üyesi
Illetişim:

Dr. Öğr. Üyesi Illknur Özkan

Akdeniz Üniversitesi Kumluca Sağlık Bilimleri Fakültesi, Hemşirelik, Antalya, Türkiye Tel: +902428870910

E-Posta: ilknurozkan@akdeniz.edu.tr
Gönderilme Tarihi : 31 Mayıs 2018

Revizyon Tarihi : 05 Temmuz 2018

Kabul Tarihi : : 07 Temmuz 2018

\section{ÖZET}

Amaç: Araştırma, Kumluca ilçesinde öğrenim gören üniversite öğrencilerinin obezite hakkındaki farkındalıkları ile beden kitle indeksleri arasındaki ilişkinin değerlendirilmesi amacılla planlanmıştır.

Yöntem: Kesitsel türde yapılan bu araştırmada örneklem seçimine gidilmeden Akdeniz Üniversitesi Kumluca Meslek Yüksek Okulu'nda 2017-2018 eğitim ve öğretim yılı içerisinde öğrenim gören, çalışmaya katılmayı kabul 176 öğrenci dahil edilmiştir. Verilerin toplanmasında, Obezite Farkındalık Ölçeği (OFÖ) ve araştırmacılar tarafından hazırlanan sosyo-demografik bilgi formu kullanıımıştı. Öğrencilerin Beden Kitle İndeksini (BKI) değerlendirmek amacılyla boy ve kiloları araştırmacilar tarafından ölçülmüştür. Verilerin analizinde tanımlayıc istatistiklerin yanı sıra, Mann Whitney-U, Kruskal-Wallis varyans analizi ve Spearman korelasyon analizi kullanılmıştır.

Bulgular: Araştırmada öğrencilerin yaş ortalaması $20,25 \pm 2,69$ yıl ve $\% 58^{\prime}$ i erkek olarak belirlenmiştir. Öğrencilerin $\% 35,2^{\prime}$ sinin sigara ve $\% 34,7$ 'sinin alkol kullandığı saptanmıştır. Öğrencilerin $\% 60,2$ 'si düzenli fiziksel aktivite yapmadığını ve $\% 46$ 'sı öğünlerini düzenli olarak tüketmediklerini belirtmişlerdir. Öğrencilerin $\% 40,3^{\prime} \mathbf{u}$ fazla kilolu olarak değerlendirilirken, $\% 11,4^{\prime} \mathbf{u ̈ ~ o b e z ~ o l a r a k ~}$ değerlendirilmiştir. Öğrencilerin OFÖ'den ve alt boyutlarından aldıkları puanlar incelendiğinde, öğrencilerin obezite farkındalık alt boyutundan $26,55 \pm 6,59$, beslenme alt boyutundan $18,2 \pm 4,37$ fiziksel aktivite alt boyutundan $14,7 \pm 3,60$ puan aldıkları bulunmuştur. Öğrencilerin BKI değerleri ile OFÖ toplam ve alt boyut puanları arasındaki ilişki incelendiğinde; negatif yönlü ancak anlamlı olmayan bir ilişki olduğu tespit edilmiştir.

Sonuç: Çalışmamızda üniversite öğrencilerinin obezite hakkındaki farkındalıkları diğer çalışmalara göre daha düşük; fazla kilo ve obezite prevalansı ise yüksek olarak saptanmıştır. Üniversite yılları sağlık yaşam biçim davranışlarını geliştirmek için önemli bir fırsattır. Üniversite öğrencileri, sağııksız diyet ve sedanter alışkanlıklar gibi riskli davranışların önlenmesi konusunda desteklenmeli ve obezite hakkında farkındalığı artıracak eğitimler düzenli olarak planlanmalıdır.

Anahtar sözcükler: Üniversite, öğrenciler, obezite, farkındalık, beden kitle indeksi

\section{RELATIONSHIP BETWEEN BODY MASS INDEX AND OBESITY AWARENESS OF UNIVERSITY STUDENTS}

\section{ABSTRACT}

Objective: This research was planned with the aim of assessing the relationship between awareness about obesity and Body Mass Index (BMI) of students who study in Kumluca.

Materials and Methods: 176 students who study at Akdeniz University, Kumluca Vocational School, in the 2017-2018 academic year and accept to participate in the study without doing sample selection in this cross-sectional type of research were included in the study. In data collection, Obesity Awareness Scale (OAS) and socio-demographic form developed by researchers were used. In addition to descriptive statistics in data analysis, Mann Whitney-U, Kruskal-Wallis analysis of variance and Spearman's Rank correlation were used.

Results: Age average of the students was found as $20.25 \pm 2.69$ year and $58 \%$ of them are male in the research. It was confirmed that $35.2 \%$ of the students smoke and $34.7 \%$ of them use alcohol. $60.2 \%$ of the students stated that they don't do physical activity and $46 \%$ of them don't eat their meals regularly. While $40.3 \%$ of the students were assessed as overweight, $11.4 \%$ of them were assessed as obese. When scores of the students in OAS and sub-dimensions of it were examined, it was found that students took $26.55 \pm 6.59$ from obesity awareness sub-dimension, $18.2 \pm 4.37$ from nutrition sub-dimension and $14.7 \pm 3.60$ from physical activity sub-dimension. When the relationship between BMI value and OAS total and sub-dimension scores of the students was examined, a relation that is negative but not significant was determined.

Conclusion: In our study, university students' awareness about obesity was lower than other studies and overweight and obesity prevalence among them was confirmed as high. University years are an important opportunity for developing healthy lifestyle behaviours. University students should be encouraged to prevent/avoid risky behaviors such as unhealthy diet and sedentary habits and education, which will increase awareness about obesity, should be planned regularly.

Keywords: University, students, obesity, awareness, body mass index 
O bezite, kardiyovasküler hastalıkların (KVH) ve mortalitenin artmasına katkıda bulunan önemli bir risk faktörüdür $(1,2)$. Son otuz yılda dünya çapında önemli ölçüde artan obezite prevalansı, 21. yüzyılın en ciddi halk sağlığı sorunlarından biridir (3). WHO'nun 2016 verilerine göre dünyada 18 yaş ve üzeri yetişkin bireylerin \%39'u fazla kilolu, \%13'ü obezdir (4). Türkiye'de ise 15 yaş ve üzeri yetişkin nüfusun \%19,9'u obez ve \%33,7'si fazla kiloludur (5).

Üniversite yılları öğrencilerin ailelerinden ayrıldıkları yeni bağımsızlıkları kazandıkları, vücuttaki hızlı değişimler, birbiriyle ilişkili değişikliklerle karakterize zihin ve sosyal ilişkiler açısından dinamik bir ara dönemdir (6). Buna ek olarak, yeni bir çevre, artan iş yükü ve stres, değişen yaşam biçimleri üniversite öğrencilerinin sağlık durumlarını olumsuz etkilemektedir (7). Yapılan çalışmalar üniversite öğrencilerinde sigara kullanımının, alkol kullanımının, sağlıksız diyet ve sedanter alışkanlıklar gibi riskli davranışların arttığını göstermektedir (8-15). Ayrıca üniversite öğrencilerinde yapılan çalışmalarda fazla kilo ve obezite prevalansının da yüksek olduğu bildirilmektedir (3,16-21). Farklı ülkelerin üniversite öğrencilerinde gerçekleştirilen çok merkezli bir çalışmada fazla kilo ve obezite prevalansının Bangladeş'de \%20,8; Çin'de \%2,9-14,3; Malezya'da \%20-\%30; Tayland'da \%31, Pakistan'da \%13\%57,6 ve Hindistan'da \%11-\%37,5; Kolombiya'da \%12,4\%16,7; Meksika: \%31,6, Kuveyt'de \%42, İran \%12,4 ve Türkiye: \%10-47 olarak belirlenmiştir (20).

Obezite, diyabet, kalp rahatsızlığı ve eklem ağrıları gibi kronik durumlar için direk bir risk faktörü olarak görüldüğü için obeziteye karşı sağlık bilgisi ve farkındalıkları belirlemek önemlidir (21). Farklı gelişmiş ülkelerde yapılan çalışmalarda, bireylerin obezitenin yaratacağı komorbid durumlarla ilgili bilgilerinin yetersiz olduğu belirlenmiştir (22-24).

Üniversite öğrencilerinde riskli sağlık davranışlarının prevalansının yüksek olmasına rağmen sağlık davranışları ve yaşam paternleri açısından en az araştırılan gruplarından biridir (25). Oysa ki; üniversite yılları sağlık yaşam biçim davranışlarını geliştirmek için önemli bir fırsattır. Genç yetişkin nüfusu temsil eden üniversite öğrencilerinin obezite hakkında farkındalıklarının ve beden kitle indekslerinin değerlendirilmesi sağlık girişimlerinin planlanması açısından önemlidir (22). Bu araştırma üniversite öğrencilerinin obezite hakkındaki farkındalıkları ile beden kitle indeksleri arasındaki ilişkinin değerlendirilmesi amacıyla yapılmıştır.

\section{Yöntem}

Araştırmanın türü

Araştırma kesitsel türde yapılmıştır.
Araştırmanın evren ve örneklemi

Araştırma Ocak-Mart 2018 tarihleri arasında Akdeniz Üniversitesi Kumluca Meslek Yüksek Okulu'nda öğrenim gören öğrencilerle yapılmıştır. Araştırmanın evrenini ilgili okulda öğrenim gören 295 öğrenci örneklemini ise çalışmaya katılmayı kabul eden 176 öğrenci oluşturmuştur.

\section{Verilerin toplanması ve veri toplama araçları}

Veriler, ders saatleri dışında sınıf ortamında öğrencilere anket formlarının uygulanması ve araştırmacılar tarafından BKI ölçümlerinin yapılması ile toplanmıştır. Öğrencilerin vücut ağırlığını ölçmek için taşınabilir dijital tartı aracı (0-150 kg), boy uzunluğu ölçmek için plastik yetişkin mezurası (0-200 cm) kullanılmıştır. BKI, kg/m² formülüyle hesaplanmıştır. Vücut ağırlığı ölçümünde öğrencilerin ayakkabı ve kalın kıyafetleri çıkarılarak ölçüm yapılmıştır.

Verilerin toplanmasında araştırmacılar tarafından hazırlanan Sosyo Demografik Özellikler Bilgi Formu ve Obezite Farkındalık Ölçeği (OFÖ) kullanılmıştır.

Sosyo Demografik Özellikler Bilgi Formu: Araştırmaya katılan bireylerin tanıtıcı özelliklerini ve sağlık davranışlarını sorgulayan 21 sorudan oluşmaktadır.

Obezite Farkındalık Ölçeği: Araştırmada kullanılan Obezite Farkındalık Ölçeği Allen (2011) tarafından geliştirilmiş toplam 23 madde ve üç alt boyuttan oluşmaktadır. Ölçek alt boyutları; a) obezite farkındalığı ( 8 madde) b) beslenme alt boyutu (7 madde), c) fiziksel aktivite alt boyutu ( 8 madde) olmak üzere 3 alt boyuttan oluşmaktadır. Ölçek olumsuzdan olumluya doğru 4'lü likert yapıdadır. Ölçeğin geneli için iç tutarlılık kat sayısı $a=0,80$ olarak bildirilmiştir. Ölçek genelinde alınan toplam puan ve alt boyutlarda elde edilen puan arttıkça farkındalık artmaktadır (26). Ölçeğin Türkçe uyarlaması Kafkas ve Özmen (2014) tarafından yapılmıştır. Ölçeğin uyarlama çalışmasında da ölçek orijinalinde olduğu gibi üç boyutlu bulunmuştur. Ölçeğin geneli için iç tutarlılık kat sayısı $a=0,87$ olarak belirlenmiştir.

F tests-ANOVA: Fixed effects, omnibus, one-way

Analysis: Post hoc: Compute achieved power

Input: $\quad$ Effect size $f \quad=0,0,25$

a err prob $\quad=0,0,05$

Total sample size $\quad=0,176$

Number of groups $\quad=0,3$

Output: Noncentrality parameter $\lambda \quad=0,11,000000$

Critical F $\quad=0,3,048212$

Numerator df $\quad=0,2$

Denominator $\mathrm{df} \quad=0,173$

Power (1- $\beta$ err prob) $=0,0,846100$ 
Çalışma sonrası yapılan güç analizinde (Post hoc) ulaşılan 176 öğrenci ile " \%2,5 etki düzeyinde \%95 güven aralığında \%84" güce ulaşıldığı bulunmuştur (G*Power 3.0.10).

\section{Verilerin Değerlendirilmesi}

Veriler, SPSS 23,0 programında değerlendirilmiş ve verilerin analizinde tanımlayıc istatistiklerin yanı sıra, sayısal değişkenler normal dağılmadığından Mann Whitney-U, Kruskal-Wallis varyans analizi ve Spearman korelasyon analizi kullanılmıştır (Kolmogorov-Smirnov değeri: $\mathrm{p}<0,05)$. Tip 1 hata düzeyinin $\% 5$ 'in altında olduğu durumlar istatistiksel anlamlılık olarak değerlendirilmiştir.

\section{Etik ilkeler}

Araştırmanın yapılabilmesi için Akdeniz Üniversitesi Tıp Fakültesi Klinik Araştırmalar Etik Kurulu'ndan izin alınmıştır (70904504/26). Uygulamadan önce öğrencilere bireysel olarak, çalışmanın amacı, anketi doldurma süresi, çalışmaya katılmanın gönüllülük esasına dayandığı, katııımlarını istedikleri zaman sonlandırabilecekleri, verdikleri bilgilerin araştırma dışında başka bir yerde kullanılmayacağı, anketlere isim yazmanın gerekli olmadığı gibi konular hakkında açıklamalar yapılmıştır. Açıklamalar sonrasında çalışmaya katılımları konusunda sözel onamları alınmıştır. Ayrıca ölçeğin çalışmada kullanılabilmesi için ölçeği geliştiren ve Türkçe'ye uyarlayan araştırmacılardan izin alınmıştır.

\section{Bulgular}

Tablo 1 incelendiğinde; öğrencilerin yaş ortalamasının 20,31 $\pm 2,92$ yıl olduğu, \%58'inin erkek, $\% 44,3$ 'ünün gelirinin giderden az olduğu bulunmuştur. Öğrencilerin \%35,2'sinin sigara ve $\% 34,7$ 'sinin alkol kullandığı saptanmıştır. Bununla birlikte öğrencilerin \%10,8'i bir sağlık sorunu olduğunu, $\% 5,7$ 'si annesinin obez olduğunu ve $\% 45,5^{\prime}$ i sağlığına bazen önem verdiğini belirtmiştir. Öğrencilerin \%40,3'ü fazla kilolu, \%11,4'ü obez olarak değerlendirilmiştir

Araştırmada öğrencilerin \%43,8'inin günlük ortalama 6-10 bardak su tükettiği, \%52,3'ünün gıdaları az çiğneme ve hızlı yeme şekliyle tükettiği ve $\% 80,1$ 'inin günlük ortalama 6-10 saat uyudukları bulunmuştur. Bununla birlikte, öğrencilerin yarıdan fazlası düzenli fiziksel aktivite yapmadığını belirtmiş $(\% 60,2)$, bunun sebebi olarak da çoğunlukla zaman yetersizliğini göstermişlerdir $(\% 37,3)$. Öğrencilerin \%54'nün öğünlerini düzenli olarak tükettikleri bulunmuştur (Tablo 2).

Obezite Farkındalık Ölçeği'nin ve alt boyutlarının özellikleri incelendiğinde, öğrencilerin obezite farkındalık
Tablo 1. Öğrencilerin tanıtıcı özelliklerinin dağııımı $(n=0,176)$

\begin{tabular}{|c|c|c|}
\hline Tanıtıcı Özellikler & Sayı & $\%$ \\
\hline \multicolumn{3}{|l|}{ Cinsiyet } \\
\hline Kadın & 74 & 42 \\
\hline Erkek & 102 & 58 \\
\hline \multicolumn{3}{|l|}{ Gelir Durumu } \\
\hline Gelir giderden az & 78 & 44,3 \\
\hline Gelir gidere eşit & 73 & 41,5 \\
\hline Gelir giderden fazla & 25 & 14,2 \\
\hline \multicolumn{3}{|l|}{ Sigara Kullanımı } \\
\hline Hayır & 114 & 64,8 \\
\hline Evet & 62 & 35,2 \\
\hline \multicolumn{3}{|l|}{ Alkol Kullanımı } \\
\hline Kullanmıyorum & 115 & 65,3 \\
\hline Ayda 1-2 kez & 38 & 21,6 \\
\hline Haftada 1-2 kez & 23 & 13,1 \\
\hline \multicolumn{3}{|c|}{ Sağlık Probleminin Varlığı } \\
\hline Var & 19 & 10,8 \\
\hline Yok & 157 & 89,2 \\
\hline \multicolumn{3}{|c|}{ Annede Obezite Varlığı } \\
\hline Var & 10 & 5,7 \\
\hline Yok & 166 & 94,3 \\
\hline \multicolumn{3}{|l|}{ Sağlığa Önem Verme } \\
\hline Evet & 79 & 44,9 \\
\hline Bazen & 80 & 45,5 \\
\hline Hayır & 17 & 9,6 \\
\hline \multicolumn{3}{|l|}{ BKi } \\
\hline Normal & 8571 & 48,3 \\
\hline Fazla kilolu & 20 & 40,3 \\
\hline Obez & & 11,4 \\
\hline \multicolumn{3}{|l|}{ Yas } \\
\hline Öğrenci & \multicolumn{2}{|c|}{$20,31 \pm 2,92$} \\
\hline Kadın & \multicolumn{2}{|c|}{$19,91 \pm 0,33$} \\
\hline Erkek & \multicolumn{2}{|c|}{$20,5 \pm 0,24$} \\
\hline
\end{tabular}

Tablo 2. Öğrencilerin alıskann|klarnın ve sağ|lk özelliklerinin dağlımı $(n=0,176)$

\begin{tabular}{lcc} 
Özellikler & Sayı & $\%$ \\
\hline Günlük Su Tüketimi & & \\
2-5 bardak & 75 & 42,6 \\
6-10 bardak & 77 & 43,8 \\
11 bardak ve üstü & 24 & 13,6 \\
\hline Yemek Yeme Şekli & & \\
Az çiğnerim hılı yerim & 92 & 52,3 \\
Çok çiğnerim yavaş yerim & 84 & 47,7 \\
\hline Günlük Uyku Süresi & & \\
3-5 saat & 24 & 13,6 \\
6-10 saat & 141 & 80,1 \\
11 saat ve üstü & 11 & 6,2 \\
\hline Düzenli Fiziksel Aktivite Yapma & & \\
Evet & 70 & 39,8 \\
Hayıı & 106 & 60,2 \\
\hline Fiziksel Aktivite Yapmama Nedeni & & \\
Ekonomik durum & 5 & 4,9 \\
Zaman yetersizliği & 38 & 37,3 \\
Alan yetersizliği & 23 & 22,5 \\
Alışkanlığın olmaması & 30 & 29,4 \\
Diğer & 6 & 5,9 \\
\hline Düzenli Öğün Tüketimi & & \\
Her zaman & 95 & 54,0 \\
Bazen & 50 & 28,4 \\
Hiçbir zaman & 31 & 17,6
\end{tabular}


alt boyutundan $26,55 \pm 6,59$, beslenme alt boyutundan $18,20 \pm 4,37$, fiziksel aktivite alt boyutundan 14,70 $\pm 3,60$ puan aldıkları bulunmuştur. Ölçeğin alt boyutlarının Cronbach's alfa değerleri sırasıyla; 0,69, 0,84, 0,82 olmak üzere ölçeğin Cronbach's alfa değeri 0,94 olarak tespit edilmiştir (Tablo 3).

Tablo 4'te öğrencilerin cinsiyetlerine, gelir durumlarına ve annede obezite varlığına göre Obezite Farkındalık Ölçeği puan ortalamaları karşılaştıııldığında, bu özellikler ile farkındalık puanları arasında farklılık saptanmamıştır $(p>0,05)$.

Tablo 5'te öğrencilerin alışkanlıkları ve sağlık özelliklerine göre OFÖ puan ortalamaları karşılaştırıldığında; sigara ve alkol kullanımı, düzenli öğün tüketimi, düzenli fiziksel aktivite ve uyku süresine göre farkındalık ölçeği puan ortalamaları arasında istatistiksel açıdan anlamlı farklııı bulunmamıştır $(p>0,05)$.

Tablo 3. OFÖ ve alt boyutlarının madde sayısı, puan ortalamaları ve

güvenirlik katsaylları

\begin{tabular}{lccccc} 
OFÖ & $\begin{array}{c}\text { Madde } \\
\text { Sayısı }\end{array}$ & $\boldsymbol{X}$ & S. S. & $\begin{array}{c}\text { Toplam Puanları } \\
\text { (Minimum-maksimum) }\end{array}$ & $\begin{array}{c}\text { Alfa } \\
\text { değerleri }\end{array}$ \\
\hline $\begin{array}{l}\text { Obezite } \\
\text { Farkındalık }\end{array}$ & 10 & 26,55 & 6,59 & $10-36$ & 0,69 \\
Beslenme & 6 & 18,20 & 4,37 & $6-24$ & 0,84 \\
Fiziksel & 4 & 14,70 & 3,60 & $5-20$ & 0,82 \\
Aktivite & & & & & \\
Toplam & 20 & 57,06 & 9,26 & $21-80$ & 0,94
\end{tabular}

Öğrencilerin BKI değerleri ile OFÖ toplam ve alt boyut puanları arasındaki ilişki incelendiğinde; BKI ve obezite farkındalık alt boyut puanları arasında negatif yönlü ancak anlamlı olmayan bir ilişki olduğu; beslenme, fiziksel aktivite alt boyutu ve ölçek toplam puanı arasında pozitif yönlü ancak anlamlı olmayan bir ilişki olduğu tespit edilmiştir (Tablo 6).

\section{Tartışma}

Yüksek BKI, son yirmi yılda dünya çapında en büyük halk sağlığı sorunlarından biri haline gelmiştir. Genel popülasyonda 25 kg/m2 üzerindeki BKi'nin kardiyovasküler, metabolik ve kas-iskelet sistemi hastalıkları için bir risk faktörü olduğu açıkça belgelendirilmiştir (27). Yakın tarihli bir çalışma, çocuklarda, ergenlerde ve yetişkinlerde aşırı kilo/obezite durumunun son kırk yıl içinde özellikle yüksek ve orta gelirli ülkelerde 10 kat yükseldiğini göstermiştir (1). Düşük-orta gelirli ve ekonomisi gelişmekte olan 22 ülkenin üniversite öğrencilerinde yapılan çok merkezli bir çalışmada fazla kilo ve obezite prevalansı \%22 olarak belirlenmiştir (20). Issa (2015)'nın Sudi Arabistan'da 1473 erkek üniversite öğrencisinde yaptığı çalışmada $\% 28,5^{\prime} \mathrm{i}$ fazla kilolu ve \%16'sı obez olarak değerlendirilmiştir. Türkiye'de üniversite öğrencilerinde yapılan çalışmalara baktığımızda; Soyuer ve ark. (2010)'nın çalışmasında öğrencilerin \%8,5 obez; Dülger ve Mayda'nın (2016) çalışmasında öğrencilerin \%18,8'i fazla kilolu, \%4,9'u obez; Zileli ve ark. (2016)'ın çalışmasında öğrencilerin \%22'si fazla kilolu, \%6,3'ü obez; Yıldırım ve ark. (2017)'nın çalışmasında öğrencilerin \%23,12'si fazla kilolu, \%10,1'i obez olarak değerlendirilmiştir. Çalışmamızda üniversite öğrencileri

Tablo 4. Öğrencilerin tanıııcı özelliklerine göre obezite farkındalık ölçeği puan ortalamalarının karşılaştıııması

\begin{tabular}{|c|c|c|c|c|c|c|c|c|c|}
\hline \multirow[t]{2}{*}{ Özellikler } & \multicolumn{2}{|c|}{ Obezite Farkındalık } & \multicolumn{2}{|c|}{ Beslenme } & \multicolumn{2}{|c|}{ Fiziksel Aktivite } & \multicolumn{2}{|c|}{ OFÖ Toplam } & \multirow[b]{2}{*}{ Fark } \\
\hline & $x$ & S. S. & $x$ & S. S. & $x$ & S. S. & $x$ & S. S. & \\
\hline $\begin{array}{l}\text { Cinsiyet } \\
\text { Kadın } \\
\text { Erkek }\end{array}$ & $\begin{array}{l}26,83 \\
26,30\end{array}$ & $\begin{array}{l}4,71 \\
7,72\end{array}$ & $\begin{array}{l}18,77 \\
17,73\end{array}$ & $\begin{array}{l}3,50 \\
4,88\end{array}$ & $\begin{array}{l}15,04 \\
14,63\end{array}$ & $\begin{array}{l}3,02 \\
3,99\end{array}$ & $\begin{array}{l}60,64 \\
58,33\end{array}$ & $\begin{array}{l}9,86 \\
1,48\end{array}$ & - \\
\hline Test ve Anlamlılık & \multicolumn{2}{|c|}{$\begin{array}{c}U=3526,00 \\
p=0,523\end{array}$} & \multicolumn{2}{|c|}{$\begin{array}{c}U=3348,50 \\
p=0,383\end{array}$} & \multicolumn{2}{|c|}{$\begin{array}{c}U=3632,50 \\
p=0,836\end{array}$} & \multicolumn{2}{|c|}{$\begin{array}{c}U=9274,00 \\
p=0,433\end{array}$} & \\
\hline $\begin{array}{l}\text { Gelir durumu } \\
\text { Gelir giderden az } \\
\text { Gelir gidere eşit } \\
\text { Gelir giderden fazla }\end{array}$ & $\begin{array}{l}26,78 \\
27,05 \\
24,40\end{array}$ & $\begin{array}{l}5,72 \\
7,07 \\
7,50\end{array}$ & $\begin{array}{l}18,29 \\
18,38 \\
17,36\end{array}$ & $\begin{array}{l}4,14 \\
4,16 \\
5,59\end{array}$ & $\begin{array}{l}15,15 \\
14,84 \\
13,52\end{array}$ & $\begin{array}{l}3,55 \\
3,38 \\
4,21\end{array}$ & $\begin{array}{l}60,23 \\
59,85 \\
55,28\end{array}$ & $\begin{array}{l}1,25 \\
1,20 \\
1,62\end{array}$ & - \\
\hline Test ve Anlamlılık & \multicolumn{2}{|c|}{$\begin{array}{c}\mathrm{KW}=1,763 \\
\mathrm{p}=0,414\end{array}$} & \multicolumn{2}{|c|}{$\begin{array}{c}K W=0,267 \\
p=0,875\end{array}$} & \multicolumn{2}{|c|}{$\begin{array}{c}K W=3,205 \\
p=0,201\end{array}$} & \multicolumn{2}{|c|}{$\begin{array}{c}K W=1.250 \\
p=0,535\end{array}$} & \\
\hline $\begin{array}{l}\text { Annede obezite varlığı } \\
\text { Var } \\
\text { Yok }\end{array}$ & $\begin{array}{l}24,30 \\
26,69\end{array}$ & $\begin{array}{l}8,39 \\
6,49\end{array}$ & $\begin{array}{l}16,70 \\
18,29\end{array}$ & $\begin{array}{l}5,75 \\
4,29\end{array}$ & $\begin{array}{l}14,10 \\
14,83\end{array}$ & $\begin{array}{l}4,43 \\
3,57\end{array}$ & $\begin{array}{l}55,10 \\
59,63\end{array}$ & $\begin{array}{l}1,82 \\
1,26\end{array}$ & \multirow[t]{2}{*}{-} \\
\hline Test ve Anlamlılık & \multicolumn{2}{|c|}{$\begin{array}{c}U=751,00 \\
p=0,633\end{array}$} & \multicolumn{2}{|c|}{$\begin{array}{c}U=732,50 \\
p=0,570\end{array}$} & \multicolumn{2}{|c|}{$\begin{array}{c}U=760,50 \\
p=0,698\end{array}$} & \multicolumn{2}{|c|}{$\begin{aligned} U & =750,00 \\
p & =0,672\end{aligned}$} & \\
\hline
\end{tabular}


Tablo 5. Öğrencilerin alışkanlıkları ve sağlık özelliklerine göre obezite farkındalık ölçeği puan ortalamalarının karşılaştıııması

\begin{tabular}{|c|c|c|c|c|c|c|c|c|c|}
\hline \multirow[t]{2}{*}{ Özellikler } & \multicolumn{2}{|c|}{ Obezite Farkındalık } & \multicolumn{2}{|c|}{ Beslenme } & \multicolumn{2}{|c|}{ Fiziksel Aktivite } & \multicolumn{2}{|c|}{ OFÖ Toplam } & \multirow[b]{2}{*}{ Fark } \\
\hline & $x$ & S.S. & $x$ & S.S. & $x$ & S.S. & $x$ & S.S. & \\
\hline $\begin{array}{l}\text { Sigara kullanımı } \\
\text { Hayır } \\
\text { Evet }\end{array}$ & $\begin{array}{l}26.14 \\
27.32\end{array}$ & $\begin{array}{l}4.89 \\
8.91\end{array}$ & $\begin{array}{l}18.42 \\
17.78\end{array}$ & $\begin{array}{l}3.73 \\
5.38\end{array}$ & $\begin{array}{l}14.72 \\
14.91\end{array}$ & $\begin{array}{l}2.93 \\
4.63\end{array}$ & $\begin{array}{l}59.28 \\
59.51\end{array}$ & $\begin{array}{l}1.03 \\
1.70\end{array}$ & - \\
\hline Test ve Anlamlılık & \multicolumn{2}{|c|}{$\begin{array}{c}U=3082,50 \\
p=0.161\end{array}$} & \multicolumn{2}{|c|}{$\begin{array}{c}U=3460,00 \\
p=0.957\end{array}$} & \multicolumn{2}{|c|}{$\begin{array}{c}U=3095,00 \\
p=0.228\end{array}$} & \multicolumn{2}{|c|}{$\begin{array}{c}U=3801,50 \\
p=0.346\end{array}$} & \\
\hline $\begin{array}{l}\text { Alkol kullanımı } \\
\text { Kullanmıyorum } \\
\text { Ayda 1-2 kez } \\
\text { Haftada 1-2 kez }\end{array}$ & $\begin{array}{l}26.45 \\
28.89 \\
25.14\end{array}$ & $\begin{array}{l}5.12 \\
8.48 \\
7.05\end{array}$ & $\begin{array}{l}19.48 \\
18.36 \\
16.42\end{array}$ & $\begin{array}{l}3.91 \\
3.86 \\
4.92\end{array}$ & $\begin{array}{l}14.82 \\
16.00 \\
14.14\end{array}$ & $\begin{array}{l}3.19 \\
3.33 \\
3.80\end{array}$ & $\begin{array}{l}59.64 \\
63.69 \\
55.71\end{array}$ & $\begin{array}{l}1.10 \\
1.23 \\
1.52\end{array}$ & - \\
\hline Test ve Anlamlılık & \multicolumn{2}{|c|}{$\begin{array}{c}K W=2,255 \\
p=0.240\end{array}$} & \multicolumn{2}{|c|}{$\begin{array}{c}\mathrm{KW}=6,046 \\
p=0.049\end{array}$} & \multicolumn{2}{|c|}{$\begin{array}{c}K W=4,173 \\
p=0.124\end{array}$} & \multicolumn{2}{|c|}{$\begin{array}{c}K W=4,583 \\
p=0.101\end{array}$} & \\
\hline $\begin{array}{l}\text { Düzenli öğün tüketimi } \\
\text { Her zaman } \\
\text { Bazen } \\
\text { Hiçbir zaman }\end{array}$ & $\begin{array}{l}26.34 \\
26.44 \\
27.38\end{array}$ & $\begin{array}{l}7.18 \\
4.74 \\
4.06\end{array}$ & $\begin{array}{l}17.60 \\
18.68 \\
19.30\end{array}$ & $\begin{array}{l}5.00 \\
4.46 \\
3.21\end{array}$ & $\begin{array}{l}14.43 \\
15.08 \\
15.41\end{array}$ & $\begin{array}{l}4.02 \\
2.91 \\
3.20\end{array}$ & $\begin{array}{l}57.94 \\
60.20 \\
62.43\end{array}$ & $\begin{array}{l}1.50 \\
9.95 \\
9.45\end{array}$ & - \\
\hline Test ve Anlamlılık & \multicolumn{2}{|c|}{$\begin{array}{c}K W=0,952 \\
p=0.621\end{array}$} & \multicolumn{2}{|c|}{$\begin{array}{c}K W=2,514 \\
p=0.284\end{array}$} & \multicolumn{2}{|c|}{$\begin{array}{c}K W=1,042 \\
p=0.594\end{array}$} & \multicolumn{2}{|c|}{$\begin{array}{c}K W=1,698 \\
p=0.428\end{array}$} & \\
\hline $\begin{array}{l}\text { Düzenli fiziksel aktivite } \\
\text { Evet } \\
\text { Hayır }\end{array}$ & $\begin{array}{l}25.41 \\
27.22 \\
\end{array}$ & $\begin{array}{l}7.07 \\
6.14\end{array}$ & $\begin{array}{l}17.76 \\
18.42\end{array}$ & $\begin{array}{l}5.28 \\
3.63\end{array}$ & $\begin{array}{l}14.34 \\
15.04\end{array}$ & $\begin{array}{l}4.44 \\
2.86\end{array}$ & $\begin{array}{l}57.62 \\
60.32 \\
\end{array}$ & $\begin{array}{l}1.62 \\
1.01\end{array}$ & - \\
\hline Test ve Anlamlılık & \multicolumn{2}{|c|}{$\begin{array}{c}U=3237,50 \\
p=0.181\end{array}$} & \multicolumn{2}{|c|}{$\begin{array}{c}U=3594,00 \\
p=0.930\end{array}$} & \multicolumn{2}{|c|}{$\begin{array}{c}U=3364,50 \\
p=0.394\end{array}$} & \multicolumn{2}{|c|}{$\begin{array}{c}U=10636,50 \\
p=0.460\end{array}$} & \\
\hline $\begin{array}{l}\text { Günlük uyku süresi } \\
3-5 \text { saat } \\
6-10 \text { saat } \\
11 \text { saat ve üstü }\end{array}$ & $\begin{array}{l}24.12 \\
27.14 \\
24.27\end{array}$ & $\begin{array}{l}6.57 \\
6.50 \\
6.63\end{array}$ & $\begin{array}{l}16.66 \\
18.57 \\
16.60\end{array}$ & $\begin{array}{l}4.72 \\
4.73 \\
4.74\end{array}$ & $\begin{array}{l}14.33 \\
14.86 \\
14.90\end{array}$ & $\begin{array}{l}4.22 \\
3.47 \\
4.01\end{array}$ & $\begin{array}{l}55.12 \\
60.30 \\
56.40\end{array}$ & $\begin{array}{l}1.49 \\
1.23 \\
1.50\end{array}$ & - \\
\hline Test ve Anlamlılık & \multicolumn{2}{|c|}{$\begin{array}{c}K W=5,430 \\
p=0.066\end{array}$} & \multicolumn{2}{|c|}{$\begin{array}{c}K W=4,555 \\
p=0.103\end{array}$} & \multicolumn{2}{|c|}{$\begin{array}{c}K W=0,193 \\
p=0.908\end{array}$} & \multicolumn{2}{|c|}{$\begin{array}{c}K W=3,248 \\
p=0.197\end{array}$} & \\
\hline
\end{tabular}

Tablo 6. Öğrencilerin BKI değerleri ile OFÖ toplam ve alt boyut puanları arasındaki ilişki

\begin{tabular}{cccccc} 
& & Obezite Farkındalık & Beslenme & Fiziksel Aktivite & Toplam \\
\hline BKI & $r$ & $-0,019$ & 0,007 & 0,062 & 0,014 \\
& $p$ & 0,806 & 0,930 & 0,416 & 0,860
\end{tabular}

BKI'ne göre \%40,3'ü fazla kilolu, \%11,4'ü obez olarak değerlendirildi. Çalışmamızdaki üniversite öğrencilerindeki obezite ve fazla kilolu olma oranı Türkiye'deki diğer üniversite öğrencilerinde görülen obezite ve fazla kilolu olma oranından da yüksek bulundu. Bu sonuçlar üniversite öğrencilerinde fazla kilolu ve obezite prevalansının yüksekliğini doğrulamakta ve öğrencilerin kardiyovasküler, metabolik ve kas-iskelet sistemi hastalıkları açısından yüksek risk altında olduğunu düşündürmektedir.

Çalışmalar, üniversite yıllarında yaşanan yoğun kaygı ve stresin, üniversite öğrencilerinde tütün, alkol ve madde kullanımının artırdığını göstermektedir. (28-31). 22 ülkenin üniversite öğrencilerinde yapılan çok merkezli bir çalışmada aktif sigara kullananların oranı \%27,1, alkol kullananların oranı \%24,3 olarak belirlenmiştir (9). Türkiye'de üniversite öğrencilerinde madde kullanımını değerlendirmek için yapılan araştırmalarda sigara kullanımı \%27,3 ile \%57,5; alkol kullanımı \%26,7 ile \%76 arasında değişmektedir $(28,32)$. Çalışmamızda öğrencilerin \%35,2'sinin sigara ve \%34,7'sinin alkol kullandığı saptandı. Üniversite öğrencilerinde sigara ve alkol kullanımının yüksek olduğu görülmektedir.

Günümüzde insanlar, teknolojinin yaşamı kolaylaştırması ve motorlu taşıt ulaşımının yaygınlaşması nedeniyle hareket etme ihtiyacı bile duymamaktadır. Modern çağın sorunu olan hareketsizlik ve bu kültürde büyüyen üniversite öğrencilerini de etkilemektedir. Issa (2015)'nın Sudi 
Arabistan'da 1473 erkek üniversite öğrencisinde yaptığı çalışmada; öğrencilerin fiziksel aktive düzeyi düşük bulunmuş ve inaktif ve daha az günlük aktivite yapan öğrencilerde obezite ve fazla kilolu olma oranı daha yüksek görülmüştür. Türkiye'de farklı üniversite öğrenci gruplarında yapılan çalışmalarda fiziksel aktivite düzeyleri düşük olarak değerlendirilmiştir $(12,33,34)$. Araştırmamızda da literatürde olduğu gibi öğrencilerin yarıdan fazlası düzenli fiziksel aktivite yapmadığını belirtmiştir $(\% 60,2)$.

Çalışmamızda öğrencilerin beslenme alışkanlıkları değerlendirildiğinde, \%46'sının öğünlerini düzenli tüketmedikleri belirlendi. Zileli ve ark (2016) yaptığı çalışmada üniversite öğrencilerinin \%85,1'inin öğün atladığı ve çoğunlukla atlanan öğünün sabah kahvaltısı olduğu; Onurlubaş ve ark. (2015)'nın çalışmasında da üniversite öğrencilerinin \%68,5'inin öğün atladığı saptanmıştır. Ülkemizde ve farkIı ülkelerde üniversite öğrencilerinde yapılan diğer çalışmalarda da öğün atlama oranı oldukça yüksek olduğu ve özellikle sabah kahvaltılarını atladıkları bulunmuştur $(8,11,13,15,17,20)$. Çalışmamızı ve diğer çalışma sonuçlarını göz önünde bulundurduğumuzda üniversite öğrencilerinde öğün atlamanın yaygın görülen beslenme bir bozukluğu olduğunu düşündürmektedir.

Çalışmamızda Obezite Farkındalık Ölçeği (OFÖ)'nin ve alt boyutlarından öğrencilerin obezite farkındalık alt boyutundan $26,55 \pm 6,59$, beslenme alt boyutundan $18,20 \pm 4,37$, fiziksel aktivite alt boyutundan $14,70 \pm 3,60$, ölçeğin genelinden toplam $57,06 \pm 9,26$ puan aldıkları belirlendi. OFÖ'nün Türkçeye uyarlama çalışmasında, öğrencilerinin obezite farkındalık alt boyutundan $27,36 \pm 2,18$, beslenme alt boyutundan $20,27 \pm 2,54$, fiziksel aktivite alt boyutundan $18,57 \pm 1,95$, ölçeğin genelinden toplam $65,20 \pm 6,67$ puan aldıkları belirlenmiştir (26). OFÖ'nün orijinal çalışmasında ise; öğrencilerin obezite farkındalık alt boyu-

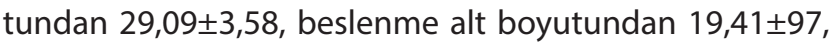
fiziksel aktivite alt boyutundan $16,90 \pm 2,23$, ölçeğin genelinden toplam $65,40 \pm 8,84$ puan aldıkları saptanmıştır (35). Çalışmamızda öğrencilerin OFÖ'den en az puanı fiziksel aktivite alt boyutundan aldığı saptandı. Bu ölçeğin orijinal formunun geliştirildiği çalışmada ve Türkçeye uyarlama çalışmasında da; öğrenciler en az puanı fiziksel aktivite alt boyuttan aldıkları belirlenmiştir. Bu verilere dayanarak öğrencilerin fiziksel aktivitenin yararları konusunda farkındalıklarının yetersiz olduğu söylenebilir. Fiziksel aktivitenin yararları konusunda düzenlenecek eğitimler üniversite öğrencilerinin farkındalıklarını artırmada önemlidir.
Çalışmamızda OFÖ'den alınan genel toplam puanı diğer çalışmalara göre daha düşüktür. Çalışmamızdaki obezite oranın yüksek olmasının sebebi farkındalığın az olmasından kaynaklanabileceğini düşündürmektedir; fakat öğrencilerin BKI değerleri ile OFÖ toplam ve alt boyut puanları arasındaki ilişki incelendiğinde; BKI ve farkındalık arasında istatiksel olarak anlamlı bir ilişki saptanmamıştır. Daha büyük örneklem gruplarında çalışılması önerilmektedir.

Çalışmamızda öğrencilerin cinsiyetlerine, gelir durumlarına ve anne ya da babada obezite varlığına sigara ve alkol kullanımına, düzenli öğün tüketimine, düzenli fiziksel aktivite yapmasına ve uyku süresine göre farkındalık ölçeği puan ortalamaları arasında istatistiksel açıdan anlamlı bir farklılık bulunmadı. Alasmari ve ark. (2017)'nın üniversite öğrencilerinde obezite farkındalığını değerlendirmek için yaptıkları çalışmada, cinsiyet, ekonomik durum, yemek alışkanlıkları, aktivite seviyeleri, sigara kullanımları, alkol kullanımları ile farkındalık puanları arasında istatiksel olarak anlamlı bir ilişki saptanmamıştır. Hassan ve ark. (2014)'nın yaptığı çalışmada ise ailede obezite öyküsü olan öğrencilerin obezite hakkındaki farkındalıkları daha yüksek bulunmuştur. Literatürde üniversite öğrencilerinde obezite hakkında farkındalığı değerlendiren başka bir çalışmaya rastlanılmamıştır. Üniversite öğrencilerinde obezite farkındalığı değerlendiren başka çalışmalara ihtiyaç olduğu görülmektedir.

\section{Sonuç}

Çalışmamızda üniversite öğrencilerinin obezite hakkındaki farkındalıkları diğer çalışmalara göre daha düşük; fazla kilo ve obezite prevalansı ise yüksek olarak saptandı. Bu sonuçlar, üniversite öğrencilerinin sağlıklı beslenmeye ve daha fazla egzersiz yapmaya odaklanan etkili obezite önleme programlarına olan ihtiyacını göstermektedir. Üniversite yılları sağlık yaşam biçim davranışlarını geliştirmek için önemli bir fırsat olarak görülmeli ve öğrenciler sağlıksız diyet ve sedanter alışkanlıklar gibi riskli davranışların önlenmesi konusunda desteklenmeli ve obezite hakkında farkındalığı artıracak eğitimler düzenli olarak planlanmalıdır.

\section{Teşekkür}

Araştırmaya katkılarından dolayı Hemşirelik Bölümü öğrencileri Sevgi Aksoy, Ömer Kaan Demirgil, Hamza Alpkaya, Nur Seda Bursalığlu, Zekiye Ergen ve Habip Gündoğdu'ya teşekkür ederiz. 


\section{Kaynaklar}

1. de Gonzalez AB, Hartge P, Cerhan JR, Flint AJ, Hannan L, Maclnnis $\mathrm{RJ}$, et al. Body-mass index and mortality among 1.46 million white adults. N Engl J Med 2010;363:2211-9. [CrossRef]

2. Jacobs EJ, Newton CC, Wang Y Patel AV, McCulluogh ML, Campbell PT, et al. Waist circumference and all-cause mortality in a large US cohort. Arch Intern Med 2010;170:1293-301. [CrossRef]

3. Nepal G, Tuladhar ET, Dahal S, Adhikari S, Kandel AG. Lifestyle practices and obesity in nepalese youth: a cross-sectional study. Cureus 2018;10:2209. [CrossRef]

4. World Health Organization, 2016. http://www.who.int/healthinfo/ EN_WHS2012_Full.pdf

5. Türkiye İstatistik Kurumu, 2014. http://www.tuik.gov.tr/ PreHaberBultenleri.do?id=0.8854

6. Pullman AW, Masters RC, Zalot LC, Carde LE, Saraiva MM, Dam YY, et al. Effect of the transition from high school to university on anthropometric and lifestyles variables in males. Appl Physiol Nutr Metab 2009;34:162-71. [CrossRef]

7. Diez SMU, Perez-Fortis SM. Socio-demographic predictors of health behaviours in Mexican college students. Health Promot Int 2010;25:85-93. [CrossRef]

8. Aydoğan Arslan S, Daşkapan A, Çakır B. Üniversite öğrencilerinin beslenme ve fziksel aktivite alışkanlıklarının belirlenmesi. TAF Prev Med Bull 2016;15:171-80. [CrossRef]

9. Crovetto M, Valladares M, Espinoza V, Mena F, Oñate G, Fernandez M, Durán-Agüero S. Effect of healthy and unhealthy habits on obesity: a multicentric study. Nutrition 2018;54:7-11. [CrossRef]

10. Du T, Zhu E, Jiao S. Poor physical performance is associated with obesity among university students in China. Med Sci Monit Basic Res 2017;23:173-8. [CrossRef]

11. Dülger $H$, Mayda AS. Bartın üniversitesi sağlık hizmetleri meslek yüksekokulu öğrencilerinde beslenme alışkanlıkları ve obezite prevalansı. Düzce Üniversitesi Sağlık Bilimleri Enstitüsü Derg 2016;6:173-7. https://dergipark.org.tr/tr/download/ article-file/343020

12. Ölçücü B, Vatansever Ş, Özcan G, Çelik A, Paktaş Y. Üniversite öğrencilerinde fiziksel aktivite düzeyi ile depresyon ve anksiyete ilişkisi. Uluslararası Türk Eğitim Bilimleri Derg 2015. ss.294-303. https://dergipark.org.tr/tr/download/article-file/408307

13. Onurlubaş $E$, Doğan HG, Demirkıran S. Üniversite öğrencilerinin beslenme alışkanlıkları. JAFAG 2015;32:61-9. [CrossRef]

14. Peltzer K, Pengpid S. The association of dietary behaviors and physical activity levels with general and central obesity among ASEAN university students. AIMS Public Health 2017;4:301-13. [CrossRef]

15. Zileli R, Cumhur Ö, Özkamçı Ö, Diker G. Üniversite öğrencilerinde beslenme alışkanlıkları ile obezite görülme sıklığı. Bilinçli Sağlıklı Yaşam Derg 2016;12:549-62.

16. Issa L. Prevalence and risk factors of obesity and overweight among Taif University Students, Taif, Saudi Arabia. Int J Public Health Epidemiol 2015;4:98-106. http://internationalscholarsjournals.org/ download.php?id=623393830621287061.pdf\&type=application/ pdf\&op $=1$

17. Pengpid S, Peltzer K. Prevalence of overweight/obesity and central obesity and its associated factors among a sample of university students in India. Obes Res Clin Pract 2014;8:e558-70. [CrossRef]

18. Ren I, Chen Y, He L, Jin Y, Tian L, Lu M, et al. Prevalence of underweight, overweight and obesity in university students from the region of Anhui (China). Nutr Hosp 2015;1:1089-93. [CrossRef]
19. Tapera R, Merapelo MT, TumoyagaeT, Maswabi TM, ErickP, Letsholo B, Mbongwe $B$. The prevalence and factors associated with overweight and obesity among University of Botswana students. Cogent Med 2017;4:1357249. [CrossRef]

20. Peltzer K, Pengpid S, Samuels A, Özcan NK, Mantilla C, Rahamefy OH, et al. Prevalence of overweight/obesity and its associated factors among university students from 22 countries. Int J Environ Res Public Health 2014;11:7425-41. [CrossRef]

21. Alasmari HD, Al-Shehri AD, Aljuaid TA, Alzaidi BA, Alswat KA. Relationship between body mass index and obesity awareness in school students. J Clin Med Res 2017;9:520-4. [CrossRef]

22. Agwu EM, Draper S, Croix MDS, Nwadiaro RE, Onuoha CR. Health rating, obesity and hypertension among university students in nigeria by gender and ethnicity. Public Health Int 2017;2:131-43.

23. Swift JA, Sheard C, Rutherford M. Trainee health care professionals' knowledge of the health risks associated with obesity. J Hum Nutr Diet 2007;20:599-604. [CrossRef]

24. Yuasa K, Sei M, Takeda E, Ewis AA, Munakata H, Onishi C, Nakahori Y. Effects of lifestyle habits and eating meals together with the family on the prevalence of obesity among school children in Tokushima, Japan: a cross-sectional questionnaire-based survey. J Med Invest 2008;55:71-7. [CrossRef]

25. Van Rensburg CJ, Surujlal N. Gender differences related to the health and lifestyle patterns of university students. Health SA Gesondheid 2013;18:1-8. [CrossRef]

26. Kafkas ME, Özen G. Obezite Farkındalık Ölçeği'nin (OFÖ) Türkçeye uyarlanması: bir geçerlik ve güvenirlik çalışması. İnönü Üniversitesi, Beden Eğitimi ve Spor Bilimleri Derg 2014;1:1-15.

27. Collaboration TERF. Separate and combined associations of body-mass index and abdominal adiposity with cardiovascular disease: Collaborative analysis of 58 prospective studies. Lancet 2011;377:1085-95. [CrossRef]

28. Atlam DH, Yüncü Z. Üniversite öğrencilerinde sigara, alkol, madde kullanım bozukluğu ve ailesel madde kullanımı arasındaki ilişki. Klinik Psikiyatri 2017;20:161-70. [CrossRef]

29. İlhan T. Üniversite öğrencilerinde yaşam amaçları ve madde kullanımı. Uşak Üniversitesi Sosyal Bilimler Derg 2013;6:183-96. https://www. pegem.net/dosyalar/dokuman/138967-20140129162928-10.pdf

30. Süngü H. Üniversite öğrencilerinin zararlı madde kullanımına ilişkin tutumları. Mutafa Kemal Üniversitesi Sosyal Bilimleri Enstitüsü Derg 2014;11:167-94. https://dergipark.org.tr/tr/download/ article-file/182928

31. Tanrıkulu AÇ, Çarman KB, Palancı Y, Çetin D, Karaca M. Kars il merkezinde çeşitli üniversite öğrencileri arasında sigara kullanım sıklığı ve risk faktörleri. Türk Toraks Derg 2009;10:101-6.

32. Turhan E, İnandıT, Özer C. Üniversite öğrencilerinde madde kullanımı, şiddet ve bazı psikolojik özellikler. Türk Halk Sağlığı Derg 2011;9:3345. https://dergipark.org.tr/tr/download/article-file/152916

33. Işık Ö, Özarslan A, Bekler F. Üniversite öğrencilerinde fiziksel aktivite uyku kalitesi ve depresyon ilişkisi. Niğde Üniversitesi Beden Eğitimi ve Spor Bilimleri Derg 2015;9:65-73.

34. Soyuer F, Ünalan D, Elmalı F. Normal ağırlıklı ve obez üniversite öğrencilerinde fiziksel aktivite. Uluslararası İnsan Bilimleri Derg 2010;7:863-72. http://www.acarindex.com/dosyalar/makale/ acarindex-1423936563.pdf

35. Allen A. Effects of educational intervention on children's knowledge of obesity risk. Phd Thesis, Carroll College. 2011; 